International Journal of Managing Information Technology (IJMIT) Vol.3, No.3, August 2011

\title{
USING A VLE TO ENHANCE 'ASSESSMENT FOR LEARNING' MATHEMATICS IN SCHOOL SCECTOR
}

\author{
Aaron Ronnie NWABUDE \\ School of Education \& Training, University of Greenwich, London UK \\ rnwabude@talktalk. net
}

\begin{abstract}
This paper investigates the use of VLE in enhancing or supporting assessment for learning mathematics by the KS4 students with special education needs in the London borough secondary school. The main challenge in teaching and learning of mathematics is to provide the special education needs students with extensive support structure that is associated with their subject area. As part of continuous teaching and learning, many schools in the UK have embraced Assessment for learning as an effective and efficient way of providing students, their teachers and their home schools with feedback and feed forward. A virtual learning environment (VLE), which is an electronic system, provides online interaction of various kinds that can take place between learners and tutors, including online learning and assessment [1]. A VLE as a platform for teaching and learning supports assessment for learning (AfL), encourages personalised and collaborative learning, enabling students to carry out peer and self assessment of mathematics course within a unified supportive environment online. Evidence from literature suggests that VLE supports out of school hours of learning, and that the special education needs learners who do not respond well to the formal structure of learning within the school system take an active part in learning in informal settings. The finding presents key issues related to mathematics teaching and assessment for learning using a VLE, based on the perspectives of the special education needs (SENs) students in the school sector. The students who received in-class feedback and feed-forward during mathematics lesson, and through the VLE (Fronter) platform, moved their learning forward and much quicker when compared with students who only received feedback in class. Correspondingly, the instant feedback provided by a VLE after the Observation stage was greatly valued by the SENs students who used this period to take greater responsibility for personal learning. In general, the finding suggests that a VLE effectively enhances assessment for Learning by offering instant feedback and feed-forward to the SENs students who, now began to take responsibility for their own learning, and have also been motivated to correct their work. Furthermore, evidence of teacher - student interactivity which facilitates greater understanding of mathematical concepts is highlighted by the study.
\end{abstract}

\section{KEYWORDS}

Virtual Learning Environment (VLE); Assessment for learning; Teaching methods; Mathematics; Key Stage 4; Secondary education sector, SENs, Technology. 
International Journal of Managing Information Technology (IJMIT) Vol.3, No.3, August 2011

\section{INTRODUCTION}

The way academic practices in higher, further and school sector education responds to the influence of computer networks and technology is central to immediate and future role of educators in creating a viable teaching and learning environment. According to [2], the process of legitimising knowledge (Justification) is a social process, and whereas knowledge is related to social action, information is conceived as a flow of messages enabling the creation of knowledge. The driver of academic practices through virtual learning is that of the creation of one's own knowledge which amplifies the process of creating meta-conceptual understanding. Today, technology resources are vital to creating an environment that is interactive and personalised. Web-based information systems including online data resources have continued to be more prevalent in our educational activities. In effect [3] states that students, teachers and school administrators now face the growing challenge of accessing data from a variety of sources. $\mathrm{He}$ went further to suggest that it is now a common place to find a multitude of WebCT-based systems in a typical school, college or academy environment that teachers and students are required to use as part of their daily routine (Greenwood, 2010). In 2008, most schools in England were encouraged to embrace the use of virtual learning environment (VLE) in preparation, teaching and delivering of lessons to students [4]. Since then, the VLEs have been adopted by schools for teaching, learning and assessment. A VLE has many benefits and functions that would support students' progression in their courses, particularly the special educational needs students in areas such as out-of schools learning of mathematical courses, personalised, immediate in-class and out of school assessment systems [5]. A virtual learning environment (VLE) is a set of teaching and learning tools designed to enhance a student's learning experience by including computers and the internet in the learning process. A VLE provides components in which learners and tutors participate in several on-line interactions, including on-line learning [6]. The principal components of a VLE package include curriculum mapping (breaking curriculum into sections that can be assigned and assessed), student tracking, online support for both teacher and student, electronic communication (e-mail, threaded discussions, chat, Web publishing), and internet links to outside curriculum resources [7]. The VLEs offer the ability to schedule a range of learning activities and make tools available rather than just manage content [8]. Users are able to explore social situations and "try out" different behaviour responses for a variety of simulated social interactions [9]. A number of VLE software packages are available in the market, including Blackboard, Fronter, WebCT, Lotus Learning Space, Moodle, COSE, Maths-Lab, Broad-works and Method-maths. The virtual learning environment (VLE) as a supportive tool in education enables appropriate modification in

curriculum, teaching methods, personalised assessment, educational resource, medium of communication or the learning environment in order to cater for individual differences in learning [10]. [11]' advocate that the VLEs are particularly useful for people with autism and may provide the ideal method for social skills training. Similarly, research conducted by [12]' shows that 'learners with special needs in mainstream schools are very reluctant to follow a curriculum which they perceive as having little 'surrender value. It is therefore, my contention that a VLE will enable such learners to acquire skills necessary for today's job market. For the purpose of this paper, special education needs refer to a range of educational and social services provided by the public school system and other educational institutions to individuals with disabilities who are in their KS4 sessions and between 14-16 years of age. 
International Journal of Managing Information Technology (IJMIT) Vol.3, No.3, August 2011

\section{BACKGROUND AND RELATED WORK}

The study describes a pilot project aimed at using a virtual learning environment (VLE) to facilitate assessment for learning mathematics by the special education needs students (SENs) at KS4 mathematics course in the secondary school. There has always been an interest in the assessment for learning within the virtual learning environment (VLE) platform. While we recognise the importance of technology in enhancing teaching and learning in the Universities and colleges, the benefits of its capabilities and potentials have thus not been realised in the school sector education. Some scholars, notably; [13], [4], [14] have argued that successful use of a VLE in teaching, and assessment for learning is dependent upon the knowledge of teachers who use this technology to teach and assess learners' acquisition of knowledge and skills. A good grasp of information technology was not crucial to a good VLE; they flourished where skilled and confident teachers treat the VLEs as extension of their normal work [14]. The assessment for learning forms the building block upon which other parts of teaching and learning; students' motivation, personalisation of learning, feedback and feed-front, out of school learning and others are built upon.

\subsection{Assessment for Learning - What is?}

Assessment for learning has become an integral part of teaching and learning in various schools, and finding an effective and efficient way of giving feedback and feed forward has become a priority for some schools in the United Kingdom. Assessment for learning has been defined by some authors as; "The process of seeking and interpreting evidence for use by learners and their teachers in deciding where the learners are in their learning, where they need to go and how to get there" [15]. Another definition of assessment for learning which includes a working definition from widely cited article - Wikipedia, the free encyclopaedia contends that: "the term 'assessment' refers to all those activities undertaken by teachers, and by their students in assessing themselves, which provide information to be used as feedback for the modification of teaching and learning activities in which they are engaged". These definitions underpin the need for a VLE platform in supporting assessment for learning. Similarly, studies conducted by [16] on the assessment, and the use of ICT confirms that ICT - WebCT has the functionality of playing a pivotal role in enabling data collection and manipulation to be carried out easily and efficiently. It can, for example, be used to analyse individual special education needs (SENs) student's attainment and set target for that student. The Virtual learning environments (VLEs) are claimed to offer schools a number of benefits, such as anytime, anywhere access, improved motivation, access to higher or novel learning styles, opportunities for independent learning, better integration of information and communication technology (ICT) tools, and increased parental engagement [17]. In today's world where we become more dependent on machinery and technology in our daily lives [18], virtual learning has become one of the ways technology has been used to supplement learning and assessment. According to [19], a typical virtual learning environment consists of course details and objectives, lectures notes, summaries, reading lists, learning resources, computer-assisted materials, discussion groups and assessment. The tools and privileges attributed to tutor differ from that of the student; for instance, a tutor would normally be able to add scores of all students and update students' assessment information, unlike a student participant. The importance of using a VLE to support assessment for learning has also been reiterated by the Department for Children, Schools and Families (DCSF), formally known as Department for Education and Skills [20]. A VLE provides the platform and the means by which 
International Journal of Managing Information Technology (IJMIT) Vol.3, No.3, August 2011

teachers can give (students) feedback that is direct to the individual performance and needs. This capitalises on the interactivity offered by computer, that is, the teacher and learners communicate by the use of a VLE technology as a medium, in a way that supports learning which can be personalised and direct to SENs students" [20]. The SEN policy addresses the use of Technology in order to enhance the learning of students with special educational needs. The VLE and other WebCT are written to ensure that all students develop ICT capability in line with their ability level. The use of generic software and the standard applications support achievement in students with special educational needs. The virtual learning environment offers SEN (Special Education Needs) students a specialised area where they are able to use the VLE and ICT to support their learning. The use of VLE in subject areas such as Mathematics is a statutory requirement within the National Curriculum at both KS3 and KS4 [20], thus the belief that many schools in the UK have developed effective practice in a VLE technology. Ofsted states that "ICT teaching at KS3 is now more challenging than previously, with well planned discrete courses; most learners now achieve well" [21]. In the same report however, the continual weaknesses in the VLE technology assessment for learning were noted. It argues that weaknesses continue in the assessment of learners' ICT capabilities and their own involvement, in order to promote more effective learning. Furthermore, Ofsted indicates that there is often insufficient formative assessment of learners' ICT capabilities. The secondary subject report on ICT [22] assessment, maintains that learners are insufficiently involved in their own assessment and often have too little understanding of what it is they are trying to achieve. According to DfES document [23]: "the process of work in ICT is a key in deciding standards. In making a secure judgement transparently, about the level that students have achieved, teachers must record the stages through which learners worked and the modifications and decisions they made in order to achieve their final outcome". The above, further underpins the importance of creating an effective system for learning and assessment in virtual learning environment (VLE and WebCT) technologies.

\subsection{The VLE Capabilities in Enhancing SENs Mathematical Concepts \& Assessment.}

The need to understand and be able to use mathematics in everyday life and, in the workplace has never been greater and will continue to increase" [24]. Special needs students receiving special educational services need additional opportunities and support through enhanced manipulative tools such as VLE or WebCT in order to acquire and attain a substantial understanding of important concepts, skills, and strategies relating to mathematics [24]. The special education needs (SENs) students are usually visual learners. Manipulative within the virtual learning environment platforms are therefore, an excellent tool for them to engage their learning effectively. When students work with manipulative, they are using their visual and tactile skills to enhance their learning experience. Manipulative do not only make learning easier but are also fun to work with, and most SENs students enjoy working with manipulative technology [25] as this enhances their practising number skills and use of images. The potential advantages of using computer-based manipulative technologies for teaching, learning and assessment in order to facilitate flexible provision within Mathematics has been apparent for many years [26]. [25] states that special education needs students always struggle to understand ideas that are too abstract, thus Mathematics class is particularly challenging, and while some students might be able to understand many mathematical concepts by listening to the teacher's explanation on a board, many students do not learn effectively from the instruction provided in their regular mathematics classes. For the special educational need students however, this will not be enough. They therefore often need a hands-on approach to their learning [26]. The VLEs have been embraced 
International Journal of Managing Information Technology (IJMIT) Vol.3, No.3, August 2011

by students including the SENs students and teaching staff as means of providing integrated and versatile support mechanism to school sector education, including the KS4 special needs learners. DfES [27] published article on how related technology can be used effectively to support 'Assessment for Learners' (AfL), 'states that a VLE provides a means by which teachers can give learners feedback that is direct to the individual'. This capitalises on the interactivity offered by the VLE and computer; the teachers or practitioner and learners are able to communicate using a VLE as the medium in a way that supports learning, which can be personalised and direct. Peer and self assessment can effectively be carried out within the virtual learning environment (VLE). The assessment for learning in a VLE is made easy and interesting as students obtain immediate answers from their work. Teachers introduce students to the concepts of mathematics, for example, simplifying ratios; all texts and diagrams can be edited to suit the needs and abilities of SENs learners. Teachers can then check students understanding of simplifying ratios with built-in fun activity in which students must answer correctly a range of questions on ratios. The VLE has a built-in interactive spider diagram to teach students about ratios, and students can choose to hide or reveal the answer [28]. Lesson in action can use dynamic step-by-step animation to teach students about reflection symmetry. Similarly, students' understanding can be tested with colourful slides and students must guess how many lines of symmetry each design has before revealing the answers. The reviewing and reflecting on assessment data using the VLE which has become a key feature of learning technology is the way that the assessment evidence can be collected during the learning process and stored for analysis, and can demonstrate progress over time [27]. The VLE or WebCT provides a full range of mathematics assessments to enhance instructional decisions, including a Curriculum-Based Measurement component, Pre-Test and Post-Tests, and several opportunities for ongoing assessment. Research suggests that the practice of providing feedback on a student's performance as well as information relating to the student's specific strengths and weaknesses in mathematics is a combination factor beneficial to student achievement [29].

\subsection{The School Context}

The study was piloted in a mixed comprehensive secondary school formed in 1953, and is situated within the London borough of Newham, the Olympic city. The students' population in this school is close to 2000 with age range of between 11 and 19 years. The school combines the traditional values of learning with the $21^{\text {st }}$. century learning, providing extra curriculum and exceptional extra curriculum opportunities for the students. The school provides educational services to a range of students in a multicultural, multi-ethical and multi-racial community, with a good percentage of students representing the special education needs (SENs) students. This school has been selected for the three years running for DfES School Achievement Award.

\subsubsection{What is the Study About?}

The study is about the Assessment for Learning of Mathematics coursework using a VLE platform. It is about the special education needs (SENs) students at KS4 school sector in the London Borough using their VLE in the Assessment for Learning (AfL) Mathematics coursework. 
International Journal of Managing Information Technology (IJMIT) Vol.3, No.3, August 2011

\subsubsection{Key objectives}

- To check the use of the assessment for learning (AfL) technique on the students' learning

- To identify possible gains and contributions of a VLE in the mathematics coursework assessment.

- To identify examples of good practice in the Assessment for Learning on student's own work

In the UK, most schools engage in continuous monitoring, assessment and giving feedback to students both within the Web communication technology platforms and traditional (Paper based) methods. The time has come for us to ask whether teachers are making good use of available options within the VLE -ICT environment, such as word processing or spreadsheet software or even chart room in providing feedback to students. Are teachers using other features such as highlighter tool, track changes and callouts, emails, peer assessment, co-mentoring or text boxes? What are the implications for teachers? While the Department for children, schools and families (DCSF) may have the very best intentions for the use of a VLE to support the following aspects of assessment for learning; feedback on learning, peer and self assessment for learning, learners and teachers reviewing and reflecting on assessment data, there may be implications for learning. One of the implications is the setting up of acceptable VLE platform that will enhance collaboration and assessment of mathematics learning within the VLE needs through adequate curriculum planning and engagement. This has to be incorporated in the school development plan, including ICT/VLE curriculum for effective and successful use of VLE in learning and assessment. Schools in the UK usually receive ICT/VLE funding from the central government which they use in the procurement of new technology equipments such as computers, interactive whiteboard, data projectors and the VLEs. However, there is no evidence to suggest that these technologies are used effectively in the schools for the enhancement of teaching and learning with particular emphasis on the SENs students' assessment for learning in mathematics.

\section{METHODOLOGY AND APPROACH}

A group of twenty SENs students at KS4 level were used in creating a case study approach in the study, enabling me to scale down the sample size to a manageable number of students. [30]' suggests that one of the advantages of a case study is its relative importance in plotting a group's reaction to learning and teaching. The case study is an ideal research strategy when holistic, indepth investigation is needed, allowing for a mixed methods approach in gathering data. The focus of the investigation is; how would a VLE enhance and support Assessment for Learning in mathematics for KS4 students with special educational needs (SENs).

\subsection{Direct Observation}

A small focus group of SENs students with various disabilities were used to create a case study approach. Questionnaire(s) and observation tool(s) used in this study enabled me to verify technique and to ensure they are suitable. In order to gain more insight into the impact and characteristics of a VLE in the Assessment for learning, I addressed both quantitative and qualitative aspects of a VLE used in teaching and learning mathematics in the school. The operationalisation led to a standard observation scheme which includes the curriculum and didactic characteristics (whether or not specific types of VLE were used in the school for teaching and learning). 
International Journal of Managing Information Technology (IJMIT) Vol.3, No.3, August 2011

\subsection{Administering Sample Instrument}

The participants were the special education needs (SENs) students selected from a KS4 class group. This group forms a small representative part of school population. Mathematics lessons were taught to these groups over two weeks (10 day) period for one hour per lesson. Each lesson was held in the school computer/VLE room (lab room) set aside for this observational exercise. At the end of the period, a simple test plan was drawn by the teachers, where students answered questions on the virtual learning environment (VLE) platform. I entered the classroom unannounced and students were asked to fill in the questionnaires accompanying the test plan online. The answers were recorded and observation data was triangulated against the questionnaires and interview data from the teachers. The likert - type items, the alpha scale construct was carried out and Cronbach Alpha Coefficients were calculated using SPSS/PASW [31] which shows an acceptable reliability of 0.83 .

\section{RESULTS/ FINDINGS}

The research highlighted pedagogical, practical and strategic issues in using virtual learning environment (VLE) platform for assessment, especially for the special education needs (SENs) students at KS4 education sector. (By pedagogical, practical and strategic issues in using a VLE, I mean; (a) interactive mathematics teaching and learning, a measure of assessment for learning, learner centred and constructivist in nature (b) meeting students' needs, teachers' needs, time on task, reciprocity and cooperation among SENs students, and prompt feedback and (c) working understanding of the VLE, training and professional development of teachers and technologist). The study reveals that twenty students who received in-class feedback and feed-forward during mathematics lessons and via the VLE (Fronter) seem to move their learning forward and much quicker when compared with students who only received feedback in class. Similarly, evidence of teacher - student interactivity, where students receive immediate feedback during the lesson also facilitates understanding quicker than giving feedback and feed-forward through the VLE platform, especially with low ability students. It was also evident that the VLE motivates all students and supports assessment for learning (AfL); for example peer and self assessment. The study further found that the special education students were able to learn and use the VLE platform - 'Fronter' (school version) to set target and manage their learning. The mathematics teacher was able to create new conversation and teach students new lessons for a period of ten days. At the end of the ten - day period, students were assessed. The study suggests that students were able to set their personal goals and carry out self assessment when directed by the teacher. There is a direct confirmation from the study that the VLE - 'Fronter' strongly supports all the elements of curriculum on mathematics entitlement and choice. Students were actively involved in the process of learning and assessment within the VLE - Fronter. They were enthused at the extent to which they have used the platform as a learning tool, which underpins the argument that a VLE contributes to learning and teaching of students. There is evidence from the analysis of data collected via the VLE that those students who receive constant feedback and guidelines for improvement, both in the class and through the VLE, performed better than other students who did not. The VLE offers students in the research group an opportunity to self assess their work in real time to see how they have performed and possible areas of improvement before finally uploading their work. These students were able carry out peer assessment by first, saving their work in the student folder; this allowed other students to access these work and make comments. The personalised access to learning and assessment were achieved as students were given feedback and feed-forward that is relative to their ability. This also promotes independent and 
International Journal of Managing Information Technology (IJMIT) Vol.3, No.3, August 2011

interactive learning which in my view raises confidence and engagement level of the SENs on their learning process. All the students indicated that they enjoyed using the VLE to carry out peer assessment exercise since it availed them the opportunity to look at other student's work in order to give feedback and gain more understanding. The students confirmed that it was helpful to receive feedback and guidelines on the required work improvement from fellow students, and able to carry out peer and self assessments.

\subsection{Perceived Impact}

The result of perceived impact of the VLE on students' learning before and after the observation on a VLE (Fronter) shows that majority of SEN students testified that their mathematics skills was not very good before using the VLE in the mathematics class. The students' initial lack of enthusiasm and unable to discover mathematical concepts contributed to lack of skills and demotivational attitude towards mathematics, leading to under achievement and poor record in mathematics. The instant feedback provided by the VLE after the Observation stage was greatly valued by SENs students who used this period to take greater responsibility for personal learning. They also show greater motivation and confidence in their learning and assessment by correcting their works through feedback and feed forward, discovering patterns, concepts and relationships, thereby building confidence as they express themselves freely through speech and text. Review of literature seems to suggest that a VLE has added quantities of declarative knowledge and concepts to learning, thus SENs learners make more use of pictorial than abstractions. They can be good at moving images and designing objects within the VLE platform. Furthermore, the provision of access to assessment data by the students allowed teachers to address any personal or group misconceptions immediately during the lesson.

\section{CONCLUSIONS}

\subsection{The Changing Students' Roles in Learning and Assessment}

From this study, it appears that the role of learning and teaching from the perspectives of the students and the teachers are changing with out us realising this change. The special education needs students who participated in this study were enthused when introduced to the use of the VLE in a mathematics class. They showed great sense of motivation, able to personalise and move their learning forward. [32] developed a number of indicators that show how the tutor and student roles might be expected to change when moving into an online environment, for example, a virtual learning environment (VLE) platforms that offers interactive teaching, learning and assessment tools. A few of these roles include:

1. Students move from memorising facts towards solving problems;

2. Students devise their own questions and search for their own answers;

3. Students work as group members on more collaborative/co-operative assignments: group interaction significantly increased;

4. Discussion of students' work in the classroom and peer to peer assessment is effective;

5. There is a change in emphasis from receiving information from the teacher and learning to 'pass the test' towards using knowledge; 
International Journal of Managing Information Technology (IJMIT) Vol.3, No.3, August 2011

The benefits of using a VLE has been embraced by students and teaching staff as a means of providing integrated and versatile support mechanism for students' assessment. The study notes that virtual learning environment (VLE) supports assessment for learning (AfL), personalised, autonomous and collaborative learning. However, there was also a concern that mere use of a VLE may not bring about significant improvement in students learning and assessment. The learning pathway functionality of a VLE; whichever version used, allows for greater differentiation with programmes tailored to individual student's needs, though not explored in this study. There is a substantial increase in collaborative learning between students which is attributable to the use of a VLE platform. The greatest impact of the use of a VLE can be achieved if teachers are experience users who integrate its use right from the very start of their teaching in a maths lesson. The study further revealed that teachers have yet to exploit the creative power of the VLE, in order to engage students more actively in production of knowledge. In my opinion, the impact of the VLE is dependent on the ability of teachers to fully exploit the technology effectively for pedagogical purposes; however, factors beyond teacher's control may also influence or limit the uptake. Theses factors may include; institutional cultures, leadership, financial, curriculum and assessment. In general, for schools to be able to provide inclusive and differentiated education, the use of a VLE is of necessity in our current educational dispensation.

\section{REFERENCES}

[1] Joint Information Systems Committee, (JISC) (2003), Virtual and Managed Learning Environments, http://www.jisc.ac.uk/index.cfm?name=issue_vle_mle Accessed 12/04/10

[2] Fuller, T. \& Soderlund, S. (2002), Futures; Academic practices of virtual learning by interaction. Available from: http://www.clsevier.com/locate/futures Accessed 02/02/10

[3] Greenwood, J. (2010), Using a VLE for Teaching and Learning; iCT@C, Teaching and Learning with technology http://shareit.yhgfl.net/kirklees/holmfirthhighschool/?tag=vle Accessed 01/03/10

[4] Becta (2008), Harnessing Technology Review 2008: Summary report publications. becta.org.uk/download.cfm?resID=38731

[5] Becta (2007), Personalising Learning: The Opportunities Offered by Technology. http://www.feandskills.becta.org.uk/content_files/learningand_skills/resources/ke_docs/Accessed $23 / 09 / 09$

[6] Silva, N. Costa1, GJM. Rogerson, S. \& Prior, M. (2007), Knowledge or content?. The philosophical boundaries in e-learning pedagogical theories: Research, Reflections and Innovations in Integrating ICT in Education Routledge, London, 2007 Available on http://www.formatex.org/micte2009/book/221-225.pdf Accessed 02/01/2010

[7] TechTarget, (2009), Virtual Learning Spaces; http://whatis.techtarget.com/definition/0.html Accessed 02 Jan 2010

[8] Sclater, N. (2009), Principles for the future VLE/LMS development/virtual learning: http://www.sclater.com/blog/?p=210 Assessed 27/03/10 
International Journal of Managing Information Technology (IJMIT) Vol.3, No.3, August 2011

[9] Kerr, S.J. Neale, H.R. \& Cobb, S.V. (2002), "Virtual environments for social skills training: the importance of scaffolding in practice", in Assets 2002: Proceedings of the Fifth International ACM SIGCAPH Conference on Assistive Technologies, 8-10 July, 2002, Crowne Plaza Hotel, Edinburgh, Scotland, sponsored by ACM SIGCAPH, ACM Press, New York, NY, pp. 104-10. http://portal.acm.org/citation.cfm?id=638269 Accessed 27/03/10

[10] Ministry of Education, (2009), Curriculum for Kenya Institute of Special Education Kenya Institute of Special Education: http://www.education.go.ke/SpecialEducation.php Accessed 15/10/09

[11] Williams, P. Hamid, R. Jamali, M. \& David Nicholas, (2006), Using ICT with people with special education needs: what the literature tells us. CIBER, School of Library, Archive and Information Studies (SLAIS), University College London, UK

[12] Wilson, M. \& Hash, J. (2008), Building an Information Technology Security Awareness and Training Program: NIST Special Publication 800-50 http://csrc.nist.gov/publications/nistpubs/80051/sp800-51.pdf Accessed 02 April 2009

[13] Montieth, M. and Smith, J. (2001), Learning in a virtual campus: the pedagogical implications of students' experiences, innovations in education and teaching international, 38(2) page 119-132

[14] Gilbert, C. (2009), The virtual reality of e-learning: Ofsted report 2009.

http://www.ofsted.gov.uk/Ofsted-home/News/Press-and-media/2009/January/The-virtual-realityof-e-learning Accessed 16/03/2010

[15] Assessment Reform Group (2002), Assessment for learning: 10 principles; Research based principles to guide classroom practice: Nuffield Foundation

[16] Becta (2005), Assessment and ICT: essential guides for school governors. http://files.ictopschool.net/bestanden/bronnen_digitale+genaratie/becta_review_feb05.pdfAccessed $12 / 02 / 10$

[17] Preston, D. (2004),Virtual values: The University in e-crises in Preston, D. (Ed.) Virtual learning and higher education. New York, Rapodi.

[18] Becta (2004),What the research says about virtual learning environments in teaching and learning: a literature review. http://www.partners.becta.org.uk/upload-dir/downloads/pagedocuments/research/wtrs.vles.pdf Accessed 18/12/09

[19] Waring, M. \& Boardman, (in press); Learning to Teach, Teaching to Learn: A Developmental Framework for Teacher Training; In D. Preston (Ed.) Probing the Boundaries: At the Interface. Rodolpi Publishers. http://www.lboro.ac.uk/departments/ssehs/staff/academic/mike-waring.html

[20] DfES, (2003), Access for Education for children and young people with medical needs http://publications.dcsf.gov.uk/eOrderingDownload/DEES-0732-2001.pdf.Accessed, 12/03/10

[21] OfSTED, (2003), Ofsted Reports on Mathematics in secondary schools, Ofsted publications. www.ofsted.gov.uk/maths.manchester.avb/pdf/Sec_Maths_20publication

[22] The Secondary subject report, 2000/01: (ICT) (2002), Information and communicationTechnology: OFSTED website www.ofsted.gov.uk 
International Journal of Managing Information Technology (IJMIT) Vol.3, No.3, August 2011

[23] The Standards Site, (2003) ICT at Key stage 3 Using ICT, Using ICT:

http://www.standards.dfes.gov.uk/education Accessed 17/03/10

[24] National Council of Teachers of Mathematics (2000), Principles and Standards for School Mathematics: Reston, VA: National Council of Teachers of Mathematics. National School Board Association: Technology's Impact on Learning; http://www.nsba.org/sbot/toolkit/tiol.html

[25] Scott, E. (2008), Math Manipulative for Special Ed Students; Make Math Concepts Easier to Understand http://specialneedseducation.suite101.com/article.cfm/math_manipulatives Accessed $22 / 02 / 10$

[26] Hibberd, S. Litton, C. \& Chambers, C. (2004), Mathematics Electronic Learning Environment in Engineering and Science (MELEES)

http://www.nottingham.ac.uk/pesl/resources/elearning/Accessed 18/0310

[27] DfES, (2004), Excellence and Enjoyment: Learning and teaching in the primary years: Planning and assessment for learning.

http://www.nationalstrategies.standards.dcsf.gov.uk/downloader/aa2d88403550f0e3e9eec92b494fd8. pdf_ Accessed 05/11/2009

[28] Board works, (2010), Maths, Inspiring, interactive software for teachers and students. Whole-class teaching resources www.boardworks.co.uk Bett 2010, London

[29] Gersten, R. Chard, D. J. Baker, S. K. Jayanthi, M. Flojo, J. R. \& Lee, D. S. (under review) Experimental and quasi-experimental research on instructional approaches for teaching mathematics to students with learning disabilities: A research synthesis. Review of Educational Research

[30] Hopkins, D. (2002), A Teacher's guide to Classroom Research: Maidenhead: Open University Press

[31] Field, A. (2005), Discovering Statistics Using SPSS: Second Edition, Sage publications Ltd. London.

[32] Goodyear, P. (2005), Educational design and networked learning: Patterns, pattern languages and design practice. Australasian Journal of Educational Technology University of Sydney 21(1), 82-101. 